\title{
The ups and downs of thinking about a successful other: self-construals and the consequences of social comparisons
}

\author{
MARKUS KEMMELMEIER* \\ AND DAPHNA OYSERMAN \\ University of Michigan, USA
}

\begin{abstract}
We hypothesized that the consequences of upward social comparisons are mediated by independent versus interdependent content of self-construals. Independent self-construals emphasize personal uniqueness; thus comparison to an outstanding other should undermine one's sense of uniqueness and lower current self-evaluations. Conversely, interdependent self-construals focus on interpersonal connectedness. Hence, interdependent individuals should be able to bask in the reflected success of a personally relevant other in an upward comparison task, thus increasing self-evaluations. In a study involving 66 US undergraduates the latter predictions were supported. The psychological dimension of interdependence predicted differential outcomes of upward social comparisons, but this was not the case for the dimension of independence. Also, differential consequences of social comparison were more pronounced for current self-evaluations than for participants' possible selves. Copyright (C) 2001 John Wiley \& Sons, Ltd.
\end{abstract}

Ever since Festinger's (1954) seminal paper, students of social comparison processes have struggled with the question of how comparisons with outstanding others influence self-views (Blanton, in press; Brickman \& Bulman, 1977; Collins, 1996; Taylor \& Lobel, 1989; Tesser, 1991). Although in the absence of a salient standard, self-evaluations are generally positive, upward social comparisons with an other who is doing better than the self can highlight one's imperfections and thus have a sobering effect, lowering mood, dampening self-worth and self-competence. Indeed, many studies confirm that exposure to a high performing other dampens self-assessments (e.g. Gilbert, Kiesler, \& Morris, 1995; Morse \& Gergen, 1970; Lockwood \& Kunda, 1997; Pelham \& Wachsmuth, 1995). These studies suggest that when an other's highly successful performance is made salient self-evaluations tend to shift away from the target, becoming more negative. Social judgment researchers label this shift in the valence of self-assessment away from the target a contrast effect (e.g. Eiser, 1990; Martin, 1986; Schwarz \& Bless, 1992; Sherif \& Hovland, 1961). However, social comparison research has also documented self-assessment shifts in the opposite direction, toward the target, such that in the context of a successful other, self-ratings become more positive than they would have been without the salient

*Correspondence to: Markus Kemmelmeier, Department of Psychology, University of Michigan, Ann Arbor, MI 48109-1109, USA. E-mail: markusk@umich.edu 
comparison target (Lockwood \& Kunda, 1997; Taylor \& Lobel, 1989). This shift has been described as 'basking in the reflected glory' of the other, associating oneself with the other's successes (Cialdini, Borden, Thorne, Walker, Freeman, \& Sloan, 1976; Tesser, 1988). Shifting toward the successful other generally results in improved mood and self-assessments, especially when the other's glory is possibly attainable in the future (Lockwood \& Kunda, 1997). More generally, a shift in the direction of the comparison target has been termed an assimilation effect in social judgment research.

What determines whether comparison with a successful other results in assimilation or contrast effects? According to Schwarz and Bless's (1992) inclusion/exclusion model of judgment, assimilation effects occur when the target of comparison is included in the mental representation of the self or viewed as similar to the self. Conversely, contrast effects occur when the target of comparison is excluded from the mental representation of the self or viewed as distinct from the self (Schwarz \& Bless, 1992). Applying this model to the consequences of social comparisons, Blanton (in press) showed that assimilation is a common consequence when the target of comparison and the self are included within the same category. When common membership in a social group or category is salient, both upward and downward comparisons are assimilated so that the other's successes and failures are included in the self-assessment, leading to corresponding upward or downward shifts in selfjudgments. Conversely, when a common category membership is absent or not salient, contrast effects are more likely (Brewer \& Weber, 1994; for a review of this literature, see Blanton, in press).

While this research focuses on the influence of making common group membership salient, a context manipulation, it is also possible that individuals differ in their propensity to include others in the self, and that these differences can explain variability in individuals' responses to comparisons with successful others. The current research explores just this proposition. We utilize a model of the self-concept as a set of interdependent or independent self-schemas (Markus \& Kitayama, 1991; Oyserman \& Markus, 1993), and assume that self-construals are linked to self-knowledge and information about how one could become successful in various life domains. Specifically, we propose that whether upward social comparison leads to assimilation or to contrast effects depends on whether individuals tend to emphasize their interdependence with others or their independence from others.

\section{INCLUDING OR EXCLUDING THE OTHER FROM THE SELF IN UPWARD SOCIAL COMPARISON}

Markus and her colleagues proposed the term self-schemas (Markus, 1977; Markus \& Sentis, 1982) or self-construals (Markus \& Kitayama, 1991) to describe the interplay between self-concept as content and as cognitive structure and the impact of this interplay on the processing of social information. Subsequent research has focused on independent and interdependent self-construals and demonstrated the centrality of these self-construals in many areas of human functioning (Cross \& Madson, 1997; Oyserman, Coon, \& Kemmelmeier, in press). Briefly, individuals with independent self-construals value their own personal uniqueness; hence, they tend to think of themselves as distinct and different from others. Independent self-construals are associated with an emphasis on self-determination and control over one's own life. By contrast, people with relational or interdependent self-construals tend to define themselves as part of a relationship or collective. Since interdependent self-construals emphasize closeness and relatedness, individuals tend to focus on characteristics shared with important others as well as common goals. In sum, independent and interdependent self-construals are critical to how individuals think about the self in relation to others.

Given that assimilation and contrast effects in social comparison depend on how individuals view themselves vis à vis others, individual differences in independence- versus relatedness-focused 
self-construals are likely to moderate social comparison effects (cf. Taylor \& Lobel, 1989). For individuals with interdependent self-construals, social comparisons should be more likely to result in including others and others' attributes in their assessment of themselves and their possible or future selves. Conversely, when individuals with independent self-construals engage in social comparisons, they are more likely to exclude others and others' attributes in their assessment of their current or possible future selves. As a result, salient social comparisons will have differential implications for independent vs. interdependent individuals. Comparison with a salient successful target will threaten independents' feelings of positive uniqueness since in the context of a superstar, personal achievement is no longer a dimension that provides the basis for a distinct and positive sense of self. In comparison to the successful other, an independent individual will feel that their own current performance is less impressive than their self-assessment would be if the social comparison were not thrust on them. However, for interdependent individuals bringing to mind a successful target evokes a different cognitive process with starkly different outcomes. The tendency to include others in the self-concept may lead interdependent individuals to join in the other person's success, assimilating the other's success into one's sense of current and possible future success and bolstering self-evaluations (cf. Brown, Novick, Lord, \& Richards, 1992).

\section{MALLEABILITY IN COMPARISON EFFECTS ON PRESENT AND FUTURE SELVES}

As a number of theorists have emphasized, the outcome of an upward social comparison depends on the degree to which people feel they can change the behavior in question (Collins, 1996; Lockwood \& Kunda, 1997; Major, Testa, \& Bylsma, 1991). Even though exposure to a superstar may force individuals with independence focused self-construals to revise their overly generous self-views, such an upward comparison may not be threatening if the person feels that he or she has the chance to achieve similar success in the future. Whereas past and current achievements are fixed and no longer malleable, the future allows one to imagine and, possibly, attain greatness. In line with this reasoning, Lockwood and Kunda (1997, Study 2) demonstrated that upward comparison can be indeed inspiring when thinking about one's future possibilities, but sobering when evaluating current achievements. In contrast, individuals with interdependent self-construals should simply absorb the other's success whether thinking about their current or future possible selves.

In this research, we attempted to capture these disparate consequences of upward comparison simultaneously, by assessing both current self-evaluations and future or possible selves (Markus \& Nurius, 1986; Oyserman \& Markus, 1993). Specifically, with regard to current self-evaluations we expected assimilation effects for interdependent individuals and contrast for independent individuals, as described above. With regard to future self-evaluations, we expected assimilation effects for both independent and interdependent individuals, though for slightly different reasons. We anticipated that interdependent individuals would assumed to continue to simply assimilate the other into the self, while independent individuals would be inspired by an upward comparison as their future outcomes are clearly malleable.

\section{OVERVIEW}

The present study uses an individual difference approach to explore the moderating roles of selfconstruals on social comparison outcomes. We examined individual differences in independence and 
interdependence before participants in the experimental condition worked on an upward social comparison task. In doing so, we followed the recommendation of previous research to measure independence and interdependence as statistically orthogonal dimensions (cf. Bontempo, 1993; Oyserman, 1993; Singelis, 1994; Singelis, Triandis, Bhawuk, \& Gelfand, 1995). Participants in the control condition were not exposed to any social comparison. Subsequently, all participants provided self-evaluations with regard to how they felt at the present time, and concerning how they viewed themselves in the future.

\section{METHOD}

\section{Participants}

Sixty-six first-year (mean age $18.30, S D=0.50)$ primarily European American $(88 \%)$ undergraduates (42 women, 24 men) at the University of Michigan participated in this research in exchange for course credit.

\section{Materials and Procedure}

First, participants completed a series of individual difference measures including the Singelis (1994) independent self-construal scale (12 items; $\alpha=0.73$ ) and the Cross, Bacon and Morris (2000) interdependent self-construal scale (11 items; $\alpha=0.81)$. Sample independence scale items are: 'I prefer to be direct and forthright when dealing with people I've just met' and 'My personal identity, independent of others, is very important to me'. Sample interdependence items are: 'My close relationships are an important reflection of who I am' and 'I usually feel a strong sense of pride when someone close to me has an important accomplishment'.

Second, participants were randomly assigned to a no comparison-control condition or an upward social comparison condition in which they generated a relevant social comparison target. In the social comparison condition, we used a social comparison task (adapted from Oyserman, Gant, \& Ager, $1995)$ that required participants to think of someone they know who is doing very well in school. Specifically, participants were instructed to bring to mind a fellow student of their own sex and describe him or her on five blank lines. After the comparison, participants were asked to describe the nature of their relationship with the target person, the other person's age, and to rate how talented was the comparison student compared to the average student at the university. The latter rating was made on a nine-point scale with $1=$ 'average' and $9=$ 'extremely talented'. In addition, participants reported the other person's grade point average (GPA) as an indicator of the other's level of academic achievement. We also counted the overall number of words that participants used to describe their comparison target. These additions allowed us to make sure that comparisons did not differ systematically for independent vs. interdependent self-focus students. The control condition did not involve any social comparison.

\section{Dependent Variables}

Two sets of dependent variables to assess participants' current and possible future evaluations of their school performance. The current items were 'How satisfied are you with how you are doing in school 
this year?' 'Up to this point, how successful have you been in school this year?' and 'Up to this point, do you think you have fulfilled your academic potential this year?' (Cronbach's $\alpha=0.91$ ). The future items were 'How do you think you will do in school next year?' 'Overall, what are your chances of being successful in the future?' 'How easy or hard will it be for you to find a really good job when you finish school?' and 'How confident are you that you will succeed in the future?' (Cronbach's $\alpha=0.78$ ). The current and future self-evaluation items were presented in a random order. All ratings were made on a five-point scale with higher numbers reflecting self-evaluations that are more positive.

After completing the social comparison task and dependent measures, participants reported their current grade point average (GPA) as an objective measure of academic performance (two students who did not provide GPA information were dropped from analyses using GPA). Those in the upward comparison condition also provided ratings of how similar they viewed themselves vis-à-vis the comparison target, and how whether they thought their own academic performance would match that of the comparison target. Both ratings used 5-point scales.

\section{RESULTS}

\section{Descriptive Analyses}

Consistent with previous research, independence and interdependence were orthogonal, $r=-0.10, n s$, and women were higher in interdependence than men $(M=4.60, S D=0.54$ versus $M=4.22$, $S D=0.70), F(1,64)=6.20, p<0.05, \eta^{2}=0.09$ (Cross \& Madson, 1997; Cross et al., 2000). The proportion of men and women in the control and experimental conditions was comparable, $\chi^{2}(1)=0.22, n s$, and the two conditions did not differ in mean levels of independence, interdependence, or GPA (all $F \mathrm{~s}<1$ ).

\section{Manipulation Check}

Comparison targets were described using 28.56 words on average $(S D=13.38)$. The number of words in the description was inversely related to the comparison target's GPA, $r=-0.34, p<0.05$, but unrelated to independence and interdependence, $r=0.03$ and $r=-0.01$, respectively. Content analyses of descriptions of social comparison targets showed that they were close friends (33\%), casual friends such as hall mates (17\%) or friends without further specification (50\%). Relationship with target was not associated with interdependence; independence; importance of academics; target's GPA or target's rated talent (all comparisons $n s$ ).

Next, we examined whether participants had generated an upward comparison target relative to their own academic performance. Students brought to mind comparison targets who had significantly higher GPAs $(M=3.73, S D=0.19)$ than they had $(M=3.32, S D=0.46), F(1,35)=24.64, p<0.0001$, $\eta^{2}=0.41$. Participant independence and interdependence did not influence the comparison target's GPA or perceived talent (all $n s$ ). Thus, there were no systematic differences between comparison targets generated by individuals with different self-construals.

\section{Do Self-construals Moderate the Consequences of Upward Comparison?}

To test the hypothesis that self-construals have an impact on the consequences of upward comparison, we performed median splits on the independence and interdependence variables. These dichotomized 
self-construal variables were used to create a 2(experimental condition: upward comparison versus control) $\times 2$ (independence: high versus low) $\times 2$ (interdependence: high versus low) factorial design, which was used to analyze our dependent variables, current self-evaluations and future selves. The latter two variables were moderately correlated, $r=0.29, p<0.05$.

\section{Current Self-evaluation}

First, we examined the effects of upward social comparison on satisfaction with one's current academic performance. As displayed in Table 1, we found a reliable Condition $\times$ Interdependence interaction, $F(1,58)=5.32, p<0.05, \eta^{2}=0.08$, supporting our hypothesis that self-construals moderate the effects of upward comparison. Specifically, low interdependence individuals were less satisfied with their own academic performance after the upward comparison, simple main effect $F(1$, $58)=4.38, p<0.05$, replicating the classic finding that upward social comparison leads to contrast effects (e.g. Morse \& Gergen, 1970). High-interdependence individuals showed a complete reversal of this effect, feeling more satisfied with their own performance after the upward comparison, simple main effect $F(1,58)=3.33, p<0.08$. All results were replicated when participant GPA was entered as a control, supporting our prediction social comparisons result in assimilation, not contrast effects for high-interdependence individuals.

Significant effects of interdependence were not replicated with the independence analyses, neither the Condition $\times$ Independence interaction, $F(1,58)=0.16, n s, \eta^{2}<0.01$, nor the three-way interaction involving Condition, Independence, and Interdependence, $F(2,58)=0.99, n s, \eta^{2}<0.04$, were reliable. All results were replicated when we controlled for participants' GPA.

\section{Future Selves}

The analysis of this variable yielded a significant main effect for independence, $F(1,58)=4.21$, $p<0.05, \eta^{2}=0.07$. Individuals high in independence rated their possible selves more positively than did individuals low in independence ( $M=4.12, S D=0.55$ versus $M=3.77, S D=0.59$, respectively). Condition (control versus upward comparison) did not significantly influence possible self ratings, $F(1,58)<1, n s, \eta^{2}<0.01$ (upward $M=3.97, S D=0.60$ versus control $M=3.91, S D=0.60$ ). However, a partial replication of the Lockwood and Kunda (1997) assimilation effect was found for high-interdependence individuals, for whom possible selves tended to be higher after upward social comparison $(M=4.07, S D=0.52$, versus $M=3.75, S D=0.59)$, simple main effect $F(1$, 58) $=2.80, p<0.10, \eta^{2}=0.08$.

Table 1. Current self-evaluations as a function of experimental condition and level of interdependence

\begin{tabular}{lcccr}
\hline & \multicolumn{2}{c}{ Upward comparison $(n=36)$} & & \multicolumn{2}{c}{ Control $(n=30)$} \\
\cline { 2 - 3 } & $M$ & $(S D)$ & & $M$ \\
Low interdependence $(n=29)$ & 3.31 & $(0.98)$ & 4.06 & $(0.97)$ \\
High interdependence $(n=37)$ & 3.68 & $(0.79)$ & 3.15 & $(0.99)$ \\
\hline
\end{tabular}

Note: Higher values reflect more positive self-evaluations (range 1 to 5). 


\section{DISCUSSION}

Classic social comparison approaches implicitly or explicitly use independent self-construals as a standard, assuming that people are motivated mainly by their need for personal uniqueness and separateness from others. For upward comparisons, this premise leads to the assumption that the typical consequence of such a comparison is a contrast effect, dampening self-evaluations (e.g. Brickman \& Bulman, 1977; Morse \& Gergen, 1970; Pelham \& Wachsmuth, 1995). We argued that by neglecting the possibility that individuals are interdependently self-focused, the alternative, that the other's success would simply be included in the self, has not been explored sufficiently. Because individuals with interdependent self-construals include social comparison targets in their self-concepts, they are motivated to view others as related to and similar to the self, a process resulting in assimilation, not contrast (Blanton, in press). In other words, highinterdependence individuals seem to 'bask in the reflected glory' of the success of a relevant upward comparison target (Cialdini et al., 1976; Tesser, 1988). The data presented in the present study support this model.

Our model unifies a number of lines of research that suggest that upward social comparisons can result in assimilation as well as contrast effects. Thus, previous research has shown that assimilation occurs when one is asked about one's future selves and the outcome is both in one's control (Buunk, Collins, Taylor, \& Van Yperen, 1990) and attainable (Lockwood \& Kunda, 1997), one has enough information about the target (Buunk \& Ybema, 1997) to feel connected to and imagine becoming like him or her (cf. Collins, 1996). Our findings extend Lockwood and Kunda's (1997) work by showing that the malleability of own outcomes is an important factor primarily for low interdependence individuals. When these participants thought about their present self, there was a marked contrast effect. However, this contrast effect was not present when participants thought about their future, presumably because participants were able to imagine their future outcomes as more favorable than their current ones. In contrast, malleability of outcomes was not relevant for high-interdependence individuals who tended to assimilate their own views to an upward comparison target regardless of whether they thought about their present or future self.

Whereas previous research has often assumed that independent and interdependent self-construals are opposite ends of the same theoretical continuum, more recent work demonstrated independence and interdependence to be statistically orthogonal constructs (Bontempo, 1993; Oyserman, 1993; Singelis, 1994; Singelis et al., 1995). In our research, we followed the recommendation of these theorists by measuring independence and interdependence separately. Indeed, we found that only the dimension of interdependence, but not independence, constitutes the 'active ingredient' in moderating social comparison outcomes. In other words, differences in the psychological tendency to include others in the self, but not differences in the psychological tendency to view oneself as unique and distinct from others were responsible for the occurrence of assimilation or contrast. It is likely that this pattern of results was at least in part a function of our experimental paradigm in which participants brought to mind a well-performing person who they presumably knew well and were relatively close to. It is possible that the richness of knowledge participants possessed about the comparison other did not allow for the blatant self-enhancement often attributed to independent self-construals (cf. Oyserman et al., 2000). Indeed, a recent series of studies asking participant to compare themselves to a generic 'average person' found that only independence, but not interdependence, was associated with self-enhancement in self-evaluations (Kemmelmeier, Janutis, \& Gloshen, presentation at the Annual Meeting of the Midwestern Psychological Association, Chicago, IL, 1999).

The specific nature of the upward comparison may also explain why the present study did not find an overall contrast effect, the pattern typically obtained for upward comparisons. Recently, 
Mussweiler and Strack (2000) showed that upward comparisons increase the accessibility of selfknowledge that matches the good performance of the comparison other. However, whether this accessible knowledge results in assimilation or contrast effects depends mainly on whether the context emphasizes self-evaluation of one's standing relative to others, or whether the context emphasizes self-description without explicit or implicit reference to others (Mussweiler \& Strack, 2000). A review of the literature on the effects of upward comparisons shows that most experiments encouraged or even required participants to assess their standing on an evaluative dimension relative to other people. One of the clearest examples in this regard is Morse and Gergen's (1970) study in which a job applicant ('Mr Dirty') encounters a clearly superior competitor ('Mr Clean') while waiting for his job interview. In situations like this it is not surprising that participants are primarily concerned with self-evaluation relative to others, but not with mere self-description. In contrast to previous research, the present paradigm was much less explicit with regard to how the comparison information was to be used and left it up to the participants whether to use it for self-evaluation or self-description.

At this point, we speculate that the psychological dimension of interdependence reflects a differential concern with self-evaluation. Paying attention to one's own standing relative to others may be a greater priority for individuals low in interdependence who are less motivated by the goal to be connected with the comparison other. Individuals high in interdependence, on the other hand, may be more concerned with the interpersonal bond, but not necessarily with their ranking relative to others. Further, it is plausible that this difference only emerges in the absence of strong situational demands. Future research needs to address the generality of the interdependence effect found in the present study.

Critics of the present study might question the adequacy of our no-comparison control condition, as the absence or presence of a social comparison, and not the specific upward direction of the comparison may have produced the present results. We do not consider this a viable criticism. First, classic upward comparison studies have used a no-comparison control condition and found contrast effects (Morse \& Gergen, 1970). Second, while a design including an upward comparison and a downward comparison condition maximizes power, it is often unclear whether differences in such a design occur because of upward or downward shifts in self-judgments as a true control condition is absent. Only the comparison of self-evaluations in an upward comparison condition with 'natural' selfevaluations can establish the direction of judgmental shifts.

In sum, our findings demonstrate the need to take self-construals into account when theorizing the consequences of social comparisons. Our findings add to the increasing number of studies that demonstrate the impact of self-concept on the sense individuals make of the world around them. The same social event, bringing to mind a successful fellow student, can produce diametrically opposed responses, depending on whether it is seen through the perspective of an independent or interdependent mind.

\section{ACKNOWLEDGEMENTS}

The first author was supported by an ISR Founders Dissertation grant and a grant from the University of Michigan Department of Psychology. The second author would like to thank the W.T. Grant Foundation and the Center for Advanced Study in the Behavioral Sciences for its support during preparation of this manuscript. Thanks to Andrew Carrolla for his help in collecting and coding the

data. We are indebted to Roos Vonk for her thoughtful editorial comments and helpful suggestions on earlier drafts of this manuscript. 


\section{REFERENCES}

Blanton H. in press. Evaluating the self in the context of another: The three-selves model of social comparison, assimilation and contrast. In Cognitive Social Psychology: On the Tenure and Future of Social Cognition, Moskowitz GB (ed.). Erlbaum: Mahwah, NJ.

Bontempo R. 1993. Translation fidelity of psychological scales: An item response theory analysis of an individualism-collectivism scale. Journal of Cross-Cultural Psychology 24: 149-166.

Brewer MB, Weber JG. 1994. Self-evaluation effects of interpersonal versus intergroup social comparisons. Journal of Personality and Social Psychology 66: 268-275.

Brickman P, Bulman RJ. 1977. Pleasure and pain in social comparisons. In Social Comparison Processes: Theoretical and Empirical Perspectives, Suls JM, Miller RL (eds). Hemisphere: Washington, DC; 149-186.

Brown JD, Novick NJ, Lord KA, Richards JM. 1992. When Gulliver travels: Social context, psychological closeness, and self-appraisals. Journal of Personality and Social Psychology 62: 717-727.

Buunk BP, Collins RL, Taylor SE, VanYperen NW. 1990. The affective consequences of social comparison: Either direction has its ups and downs. Journal of Personality and Social Psychology 59: 1238-1249.

Buunk BP, Ybema JF. 1997. Social comparisons and occupational stress: The identification-contrast model. In Health, Coping, and Well-being: Perspectives from Social Comparison Theory, Buunk BP, Gibbons FX (eds). Erlbaum: Mahwah, NJ; 359-388.

Cialdini RB, Borden R, Thorne A, Walker M, Freeman S, Sloan L. 1976. Basking in reflected glory: Three (football) field studies. Journal of Personality and Social Psychology 34: 366-375.

Collins RL. 1996. For better or for worse: The impact of upward social comparison on self-evaluations. Psychological Bulletin 119: 51-69.

Cross SE, Madson L. 1997. Models of the self: Self-construals and gender. Psychological Bulletin 122: 5-37.

Cross SE, Bacon PL, Morris ML. 2000. The relational-interdependent self-construal and relationships. Journal of Personality and Social Psychology 78: 791-808.

Eiser JR. 1990. Social Judgment. Open University Press: Buckingham.

Festinger L. 1954. A theory of social comparison processes. Human Relations 7: 117-140.

Gilbert DT, Kiesler RB, Morris KA. 1995. When comparisons arise. Journal of Personality and Social Psychology 69: $227-236$.

Lockwood P, Kunda Z. 1997. Superstars and me: Predicting the impact of role models on the self. Journal of Personality and Social Psychology 73: 91-103.

Major B, Testa M, Bylsma WH. 1991. Responses to upward and downward social comparisons: The impact of esteem-relevance and perceived control. In Social Comparison: Contemporary theory and research, Suls JM, Wills TA (eds). Erlbaum: Hillsdale, NJ; 237-260.

Markus HR. 1977. Self-schemata and processing information about the self. Journal of Personality and Social Psychology 35: 63-78.

Markus HR, Kitayama S. 1991. Culture and the self: Implication for cognition, emotion, and motivation. Psychological Review 98: 224-253.

Markus HR, Nurius P. 1986. Possible selves. American Psychologist 41: 954-969.

Markus HR, Sentis KP. 1982. The self in social information processing. In Psychological Perspectives on the Self (Vol. 1), Suls JM (ed.). Erlbaum: Hillsdale, NJ; 41-70.

Martin LL. 1986. Set/reset: Use and disuse of concepts in impression formation. Journal of Personality and Social Psychology 51: 493-504.

Morse S, Gergen KJ. 1970. Social comparison, self-consistency, and the concept of the self. Journal of Personality and Social Psychology 16: 148-156.

Mussweiler T, Strack F. 2000. The 'relative self': Informational and judgmental consequences of comparative self-evaluation. Journal of Personality and Social Psychology 79: 23-38.

Oyserman D. 1993. The lens of personhood: Viewing the self, others, and conflict in a multicultural society. Journal of Personality and Social Psychology 65: 993-1009.

Oyserman D, Markus HR. 1993. The sociocultural self. In Psychological Perspectives on the Self (Vol. 4), Suls JM. (ed.). Erlbaum: Hillsdale, NJ; 187-220.

Oyserman D, Gant L, Ager J. 1995. A socially contextualized model of African American identity: Possible selves and school persistence. Journal of Personality and Social Psychology 69: 1216-1232. 
Oyserman D, Coon HM, Kemmelmeier M. in press. Rethinking individualism and collectivism: Research synthesis and evaluation of theoretical assumptions. Psychological Bulletin.

Pelham BW, Wachsmuth JO. 1995. The waxing and waning of the social self: Assimilation and contrast in social comparison. Journal of Personality and Social Psychology 69: 825-838.

Schwarz N, Bless H. 1992. Construction reality and its alternatives: An inclusion/exclusion model of assimilation and contrast effects in social judgment. In The Construction of Social Judgments, Martin LL, Tesser A (eds). Erlbaum: Hillsdale, NJ; 217-245.

Sherif M, Hovland CL. 1961. Social Judgment: Assimilation and Contrast Effects in Communication and Attitude change. Yale University Press: New Haven, CT.

Singelis TM. 1994. The measurement of independent and interdependent self-construals. Personality and Social Psychology Bulletin 20: 580-591.

Singelis TM, Triandis HC, Bhawuk DPS, Gelfand MJ. 1995. Horizontal and vertical dimensions of individualism and collectivism: A theoretical and measurement refinement. Cross-Cultural Research 29: 240-275.

Taylor SE, Lobel M. 1989. Social comparison activity under threat: Downward comparison and upward contacts. Psychological Review 96: 569-575.

Tesser A. 1988. Toward a self-evaluation maintenance model of social behavior. In Advances in Experimental Social Psychology (Vol. 21), Berkowitz L (ed.). Academic Press: San Diego, CA; 181-227.

Tesser A. 1991. Emotion in social comparison and reflection processes. In Social Comparison: Contemporary Research and Theory, Suls JM, Wills TA (eds). Erlbaum: Hillsdale, NJ; 115-145. 